\title{
Bacteriological Profile of Neonatal Sepsis and Antibiogram of the Isolates
}

Parajuli R' ${ }^{1}$ Pant ND², Bhandari R ${ }^{3}$, Giri A4 ${ }^{4}$, Rai S ${ }^{5}$, Acharya GP6 ${ }^{6}$ Shah PK

\begin{abstract}
Introduction: Neonatal sepsis is a serious problem in developing countries like Nepal. The main objectives of this study were to determine the bacteriological profile of neonatal sepsis, to determine the antimicrobial susceptibility patterns of the causative agents and to evaluate the association between the neonatal sepsis and the different characteristics of the neonates. Material and Methods: A hospital based cross-sectional study was conducted among a total of 450 neonates suspected of suffering from sepsis. Blood culture was performed using standard microbiological techniques. The colonies grown were identified on the basis of colony morphology, Gram's stain and biochemical tests. The antimicrobial susceptiblility testing was performed by Kirby Bauer disc diffusion method. Results: Out of total 450 blood samples, 92 (20.4\%) were culture positive. Of which, $16(17.4 \%)$ samples contained Gram negative bacilli and 76 $(82.6 \%)$ samples contained Gram positive cocci. The most common bacterial pathogens isolated were Staphylococcus epidermidis $(67.4 \%)$ followed by Escherichia coli (13\%). All Gram positive cocci were susceptible to vancomycin, while all Gram negative bacilli were sensitive to amikacin. There was statistically significant relationship between neonatal sepsis and gestation age of neonates. Conclusion: Neonatal sepsis is still present as a serious problem in Nepal. Staphylococcus epidermidis was the most common cause of the neonatal sepsis. Prematurely delivered neonates are more prone to suffer from neonatal sepsis. Vancomycin and amikacin can be used as the drugs of choice for preliminary treatment of neonatal sepsis in our settings.
\end{abstract}

Key words: Neonatal sepsis, Staphylococcus epidermidis, Escherichia coli, Nepal
${ }^{1}$ Roshan Parajuli, Department of Microbiology, St. Xaviers College, Kathmandu, Nepal. ${ }^{2}$ Narayan Dutt Pant, Department of Microbiology, Grande International Hospital, Kathmandu, Nepal, ${ }^{3}$ Raju Bhandari, Department of Microbiology, Golden Gate International College, Kathmandu, Nepal, ${ }^{4}$ Anil Giri, Department of Microbiology, Golden Gate International College, Kathmandu, Nepal, ${ }^{5}$ Suman Rai, Department of Microbiology, Tri-Chandra Multiple Campus, Kathmandu, Nepal, ${ }^{6}$ Ganesh Prasad Acharya, Paropakar Maternity and Women's Hospital, Kathmandu, Nepal, 'Pradeep Kumar Shah, Department of Microbiology, Tri-Chandra Multiple Campus, Kathmandu, Nepal.

\section{Address for correspondence Narayan D Pant Department of Microbiology, Grande International Hospital, Kathmandu, Nepal. \\ E-mail: ndpant1987@gmail.com}

\section{Acknowledgements: None \\ Funding: Nil \\ Conflict of Interest: None \\ Permission from IRB: Yes}

\section{How to cite}

Parajuli R, Pant ND, Bhandari R, Giri A, Rai S, Acharya GP, Shah PK. Bacteriological Profile of Neonatal Sepsis and Antibiogram of the Isolates. J Nepal Paediatr Soc 2017;37(1):5-9.

\section{doi: http://dx.doi.org/10.3126/jnps.v37i1.16303}

eonatal sepsis is a clinical condition characterized by systemic signs and symptoms due to bacteremia in the first month of the life $^{1}$. It is a global problem and despite the development of highly effective antibiotics and implementation of the hygiene practices in the healthcare settings, neonatal sepsis has established itself as a
This work is licensed under a Creative Commons Attribution 3.0 License. 
major cause of morbidity and mortality with high level of impact in low resource countries ${ }^{2}$. The incidence of neonatal sepsis may vary not only from developed countries to developing countries but also from hospital to hospital even in the same country ${ }^{2}$. Twenty percent of all neonates get neonatal sepsis and is the cause of $30-50 \%$ of total neonatal deaths ${ }^{3}$.

According to World Health Organization every year an estimated 1.6 million neonatal deaths occur globally with $40 \%$ of all neonatal deaths occurring in developing countries ${ }^{4}$. The risk factors those may be associated with neonatal sepsis are premature rupture of membrane, prolonged rupture, prematurity, urinary tract infection, poor maternal nutrition, low birth weight, birth asphyxia and congenital anomalies ${ }^{5}$. Neonatal sepsis may be divided into two types: early onset and late onset ${ }^{3}$. The infection acquired within $72 \mathrm{hrs}$ of age is known as early onset neonatal sepsis and the common bacteria associated with it are group B Streptococcus, Escherichia coli, coagulase negative Staphylococcus spp., Hemophilus influenzae and Listeria monocytogens ${ }^{3}$. Similarly, the infection acquired after $72 \mathrm{hrs}$ of age is known as late onset neonatal sepsis and the most common causative agents are coagulase negative Staphylococcus spp., S. aureus, Klebsiella pneumoniae, E. coli, Enterobacter spp., Pseudomonas aeruginosa and Acinetobacter spp. ${ }^{3}$.

Neonatal sepsis can be life threatening if proper treatment is not given in time ${ }^{6}$. Blood culture for the isolation of the causative agent is gold standard for identification of the cases of neonatal sepsis and the antibiotic susceptibility pattern of the bacteria isolated is necessary for giving proper treatment ${ }^{2}$. In Nepal, different studies have reported the high rates of neonatal sepsis with the bacteria showing different rates of resistance to commonly used antibiotics ${ }^{3,7}$. The microbiological pattern and antimicrobial susceptibility patterns of the causative agents of neonatal sepsis may vary from hospital to hospital and their knowledge may be helpful in timely proper management of neonatal sepsis. So, in this study we determined the rate of neonatal sepsis, bacteriological profile of neonatal sepsis and antimicrobial susceptibility patterns of the causative agents in a tertiary care hospital in Kathmandu, Nepal. Further, we also determined the association between the neonatal sepsis and the different characteristics of the neonates.

\section{Material and Methods}

A hospital based cross-sectional study was conducted among a total of 450 neonates suspected of suffering from sepsis (children with fever, breathing problem, low blood sugar, reduced sucking, low or high heart rate) at Paropakar Maternity and Women's hospital, Thapathali, Kathmandu, Nepal, a tertiary care hospital from April 2013 to September 2013. The hospital has well-equipped neonatal intensive care unit.

One $\mathrm{ml}$ of venous blood was collected using standard procedures and was inoculated into $9 \mathrm{ml}$ of brain heart infusion broth (HiMedia, India). The blood culture bottles were immediately sent to the microbiology laboratory of the Paropakar Maternity and Women's hospital. All the blood culture bottles were incubated at $37^{\circ} \mathrm{C}$ for $24 \mathrm{hrs}$ and subcultured on MacConkey agar, blood agar and chocolate agar (HiMedia, India) daily for 7 days. The inoculated MacConkey agar plates were incubated aerobically, where as blood agar and chocolate agar plates were incubated in $\mathrm{CO}_{2}$ enriched humid atmosphere using candle jar, at $37^{\circ} \mathrm{C}$ for 24-48 hours. Blood culture bottles showing no growth on subculture done after incubation of 7 days were reported as negative ${ }^{8}$. The colonies grown were identified on the basis of colony morphology, Gram's stain and biochemical tests ${ }^{9}$. The necessary patient's informations were obtained from the neonatal ward, which were entered in excel.

The antimicrobial susceptiblility testing was performed by Kirby Bauer disc diffusion method following standard guidelines and interpretive criteria of the Clinical and Laboratory Standards Institute ${ }^{10}$. For quality control of biochemical tests, purity plate was used. Similarly, for quality control of antimicrobial susceptibility testing, Escherichia coli ATCC 25922 and Staphylococcus aureus ATCC 25923 were used.

Data were analyzed using statistical package for social sciences version 16.0. Chi-square test was used and $p$-value $<0.05$ was considered as statistically significant.

\section{Results}

Out of total 450 blood samples, $92(20.4 \%)$ were culture positive. Of all 92 bacterial isolates, $16(17.4 \%)$ were Gram negative bacilli and 76 (82.6\%) were Gram positive cocci.

Different bacterial pathogens isolated from the cases of neonatal sepsis: The bacterial pathogens isolated were Staphylococcus epidermidis (67.4\%) followed by Escherichia coli (13\%), Staphylococcus aureus (9.8\%), Klebsiella pneumoniae (4.3\%), Staphylococcus saprophyticus (3.3\%) and Enterococcus fecalis $(2.2 \%)$. 
Association of sex of neonates with growth of bacteria in blood culture: Out of 450 neonates, 237 $(52.7 \%)$ were females and $213(47.3 \%)$ were males. Among males, $22.4 \%$ showed blood culture positive while $21.8 \%$ female neonates were blood culture positive. There was no statistically significant relationship between growth of organisms and sex of the neonates $(p>0.05)$.

Association of mode of delivery of neonates with growth of bacteria in blood culture: Of the 450 neonates, normal delivery was found to be occurring in highest numbers $273(60.7 \%)$ followed by caesarean delivery $152(33.8 \%)$ and instrumental delivery 25(5.6\%). It was found that neonates having normal delivery had maximum culture positive cases $(n=55)$ followed by caesarean delivery $(n=30)$ and instrumental delivery $(n=7)$. However, there was no statistically significant relationship between growth of organisms and mode of delivery of neonates $(p>0.05)$.

Association of neonatal weight with growth of bacteria in blood culture:Out of 450 neonates, $178(39.6 \%)$ neonates were born with very low birth weight $(<1500 \mathrm{~g}), 176(39.1 \%)$ with low birth weight (1500-2500g) and remaining 96(21.3\%) with good birth weight $(>2500 \mathrm{~g})$. Growth of organisms in blood was seen maximum in neonates with very low birth weight $(24.2 \%)$ followed by neonates with low birth weight $(19.3 \%)$ and neonates with good birth weight (15.6\%). But there was no statistically significant relationship between neonatal weight and growth of organisms in blood culture $(p>0.05)$

Association of gestation age of neonates with growth of bacteria in blood culture:Out of 450 neonates, $181(40.2 \%)$ were pre-term babies ( $<37$ weeks), $191(42.4 \%)$ were term babies (37-42 weeks) and $78(17.3 \%)$ were post-term babies (>42 weeks). The rate of growth of organisms was highest among pre-term babies $36.5 \%(66 / 181)$ followed by term babies $11 \%$ (21/191) and post-term babies 6.4\% (5/78). There was statistically significant relationship between growth of organisms and gestation age of neonates $(p<0.05)$.

Antibiotic susceptibility patterns of the Gram positive cocci: Among Gram positive cocci isolated, highest rate of susceptibility was seen toward vancomycin (100\%) followed by amikacin (80.3\%) (Table 1).

Antibiotic susceptibility patterns of Gram negative bacilli: Among Gram negative bacilli, the highest rate of susceptibility was seen toward amikacin (100\%) followed by cefotaxime (75\%) and ciprofloxacin (75\%) (Table 2).
Table 1: Antimicrobial susceptibility patterns of the Gram positive cocci

\begin{tabular}{lc}
\hline Antibiotics & Susceptibility (\%) \\
\hline Erythromycin & $36(47.4 \%)$ \\
\hline Gentamicin & $39(51.3 \%)$ \\
\hline Vancomycin & $76(100 \%)$ \\
\hline Amikacin & $61(80.3 \%)$ \\
\hline Cefotaxime & $48(63.2 \%)$ \\
\hline Ciprofloxacin & $51(67.1 \%)$ \\
\hline Cloxacillin & $44(57.9 \%)$ \\
\hline
\end{tabular}

Table 2: Antimicrobial susceptibility patterns of the Gram negative bacilli

\begin{tabular}{lc}
\hline Antibiotics & Susceptibility (\%) \\
\hline Ampicillin & $3(18.8 \%)$ \\
\hline Gentamicin & $10(62.5 \%)$ \\
\hline Tobramycin & $7(43.8 \%)$ \\
\hline Amikacin & $16(100 \%)$ \\
\hline Cefotaxime & $12(75 \%)$ \\
\hline Ciprofloxacin & $12(75 \%)$ \\
\hline Ceftazidime & $7(43.8 \%)$ \\
\hline
\end{tabular}

\section{Discussion}

In the developing countries like Nepal, neonatal sepsis is a serious problem ${ }^{3}$. In our study, the rate of neonatal sepsis was $20.4 \%$, which was similar to the finding by Samaga and Sumangala $(21.9 \%)^{11}$. However, higher rates were reported by Muley et al. $(26.6 \%)^{12}$, Jain et al. $(28.3 \%)^{6}$, Shrestha et al. $(30.8 \%)^{3}$, Bhatt et al. $(55.6 \%)^{13}$, Malla et al. $(57.22 \%)^{7}$ and Premalatha et al. $(82.35 \%)^{14}$, while lower rates were noted by Ansari et al. $(12.6 \%)^{15}$ and Gyawali and Sanjana $(15.13 \%)^{16}$. Use of antibiotics just after birth, effective control of nosocomial infections and infection by anaerobes may be reason for the difference in the results reported by different authors ${ }^{3}$. The patients might have got infections either from the mothers during birth or from hospital environment after birth.

As in our study, in a study by Ansari et al., among all bacterial isolates $63.8 \%$ were Gram positive isolates and $36.2 \%$ were Gram negative isolates with the commonest bacteria being coagulase negative Staphylococcus spp. followed by $S$. aureus ${ }^{15}$. Similarly, in another study by Shrestha et al. the most common organisms isolated from the cases of neonatal sepsis were $S$. aureus followed by Klebsiella pneumoniae ${ }^{3}$. Further, Gyawali and Sanjana noted the incidence of Gram positive and Gram negative organisms to be $44.1 \%$ and $55.9 \%$ respectively with Staphylococcus aureus being the predominant isolate followed by Klebsiella spp. ${ }^{16}$. However, Muley et al. showed the Klebsiella pneumoniae to be the most 
predominant pathogen followed by Staphylococcus aureus ${ }^{12}$. Accordingly, Kumaravel and Rameshbabu found the Gram negative bacteria to be predominant (88\%) with Klebsiella spp. being commonest followed by E. coli ${ }^{17}$. The causative agents of neonatal sepsis have changed over time and may vary from place to place ${ }^{15}$.

We found the statistically significant association between the gestational age and rate of neonatal sepsis with prematurely delivered neonates being at higher risk of sepsis. Similarly, Premalatha et al. found the low birth weight and prematurity to be the risk factors for neonatal sepsis ${ }^{14}$. But in our study, though highest rate of neonatal sepsis was found in the neonates with low birth weight, statistically there was no significant correlation. This may be due to the small sample size taken in our study. Premature babies have low immunity and are more prone to infection 7 . The risk factors associated with neonatal sepsis are premature rupture of membranes, prolonged rupture, prematurity, urinary tract infections, poor maternal nutrition, low birth weight, birth asphyxia and congenital anomalies ${ }^{5}$.

As we have reported, Kumaravel and Rameshbabu showed the highest rates of susceptibility of Gram negative and Gram positive bacteria toward amikacin and vancomycin respectively ${ }^{17}$. In addition, as in our study Gyawali and Sanjana found the third generation cephalosporins and aminoglycosides to be more satisfactory for Gram negative bacteria in comparison to Gram positive bacteria ${ }^{16}$. Further, Muley et al. reported the maximum susceptibility of both Gram negative and Gram positive bacteria to ciprofloxacin and amikacin ${ }^{12}$.
And suggested to use these antibiotics in empirical therapy of neonatal sepsis ${ }^{12}$. The difference in patterns of antibiotic usage in different hospitals is the main reason for the difference in antibiotic susceptibility reported by different authors.

We did not try to find out the source of infection in neonates, which is a major limitation of our study.

\section{Conclusion}

Staphylococcus epidermidis followed by Escherichia coli were the most common causes of the neonatal sepsis. Prematurely delivered neonates are more prone to suffer from neonatal sepsis. Vancomycin and amikacin can be used as the drugs of choice for preliminary treatment of neonatal sepsis in our settings. Further, cefotaxime and ciprofloxacin may be good options for treatment of neonatal sepsis caused by Gram negative bacteria.

\section{Recommendations}

Prematurely delivered neonates should be given more care, as they are more prone to suffering from neonatal sepsis. Effective infection control program including the strict hand hygiene policy should be implemented in the neonatal ward to prevent the neonatal sepsis. Further, the vaginal swab of the pregnant woman should be cultured for the detection of the colonization by the possible pathogens before delivery, so that the necessary steps can be taken to prevent the infection in neonate during birth.

Septicaemia in a Tertiary Care Hospital. Int $J$ CurrMicrobiol App Sci2015;4(10):977-84.

1. Sarangi KK, Pattnaik D, Mishra SN, Nayak MK, Jena J. Bacteriological profile and antibiogram of blood culture isolates done by automated culture and sensitivity method in a neonatal intensive care unit in a tertiary care hospital in Odisha, India. Int $J$ Advances Med2015;2(4):387-92. DOI: http://dx.doi. org/10.18203/2349-3933.ijam20151015

2. Pius S, Bello M, Galadima GB, Ibrahim HA, Yerima ST, Ambe JP. Neonatal septicaemia, bacterial isolates and antibiogram sensitivity in Maiduguri North-Eastern Nigeria. Niger Postgrad Med J 2016;23:146-51. DOI: $10.4103 / 1117-1936.190340$

3. Shrestha RK, Rai SK, Khanal LK, Mandal PK. Bacteriological study of neonatal sepsis and antibiotic susceptibility pattern of isolates in Kathmandu, Nepal. Nepal Med Coll J 2013;15(1):71-3.

4. Sawhney N, Shinu P, Singh VA.Bacteriological Profile and Antibiotic Susceptibility Pattern of Neonatal
5. Prabhu K, Bhat S, Rao S. Bacteriologic profile and antibiogram of blood culture isolates in a pediatric care unit. J Lab Physicians 2010;2:85-8. DOI: 10.4103/0974-2727.72156.

6. Jain NK, Jain VM, Maheshwari S. Clinical profile of neonatal sepsis. Kathmandu Univ Med J 2003;1 (2):11720.

7. Malla KK, Malla T, Rao KS. Bacteriological Profile of Sepsis Outbreak in the NICU of a Tertiary Care Hospital in Western Nepal. J Nepal PaediatrSoc 2013;33(1):814.DOI: http://dx.doi.org/10.3126/jnps.v33i1.7016

8. Cheesbrough M. District laboratory practice in tropical countries, part II. 2nd edition. New York: Cambridge University Press; 2006.

9. Holt JG, Krieg NR, Sneath PHA, Staley JT, Williams ST. Bergey's manual of determinative bacteriology. Williamsons and Wilkins, Baltimore. 1994. 
10. Clinical and Laboratory Standards Institute. CLSI document M100-S23. Performance standards for antimicrobial susceptibility testing; Twenty third informational supplement edition. Wayne: CLSI; 2013.

11. Samaga MP, Sumangala B. Bacteriological profile of neonatal Septicaemia in MIMS, Mandya, India. Int J CurrMicrobiol App Sci 2016;5(3):495-501.

12. Muley VA, Ghadage DP, Bhore AV. Bacteriological profile of neonatal septicemia in a tertiary care hospital from Western India.J Glob Infect Dis2015;7(2):75-7. doi: 10.4103/0974-777X.154444.

13. Bhatt SK, Patel DA, Gupta P, Patel K, Joshi G. Bacteriological profile and antibiogram of neonatal septicemia. National JCom Med 2012;3(2):238-41.
14. Premalatha DE, Koppad M, Halesh LH, Siddesh KC, Prakash N. The Bacterial Profile and Antibiogram of Neonatal Septicaemia in a Tertiary Care Hospital. Int $J$ Rec TrendsSci Tech 2014;10(3):451-5.

15. Ansari S, Nepal HP, Gautam R, Shrestha S, Neopane P, Chapagain ML. Neonatal Septicemia in Nepal: EarlyOnset versus Late-Onset/nt J Pediatr 2015;2015:379806. DOI:http://dx.doi.org/10.1155/2015/379806.

16. Gyawali N, Sanjana RK. Bacteriological profile and antibiogram of neonatal septicemia. Indian $J$ Pediatr 2013;80(5):371-4. DOI:10.1007/s12098-0120911-9.

17. Kumaravel KS, Rameshbabu B. A study of the bacteriological profile and antibiotic sensitivity in neonatal septicemia. Int J Cont Med Res 2016;3(6):1830-1. 